\title{
Richter syndrome: A rare complication of chronic lymphocytic leukemia or small lymphocytic lymphoma
}

\author{
Ewa Wąsik-Szczepanek ${ }^{1, A-F}$, Agnieszka Szymczyk 1,2,A-D,F, Dariusz Szczepanek ${ }^{3, A-F}$, \\ Joanna Wszoła-Kleinrok ${ }^{4, B-D, F}$, Sylwia Chocholska ${ }^{1, B, C, F}$, Andrzej Pluta ${ }^{5, B-F}$, Marek Hus ${ }^{1, A-F}$ \\ ${ }^{1}$ Chair and Department of Hematooncology and Bone Marrow Transplantation, Medical University of Lublin, Poland \\ ${ }^{2}$ Independent Clinical Transplantology Unit, Medical University of Lublin, Poland \\ ${ }^{3}$ Chair and Department of Neurosurgery and Pediatric Neurosurgery, Medical University of Lublin, Poland \\ ${ }^{4}$ Department of Nephrology, Endocrinology, Hypertension and Internal Diseases of Independent Public Hospital in Zamość, Poland \\ ${ }^{5}$ Department of Hematooncology, Oncology Centre, Brzozów, Poland \\ A - research concept and design; B - collection and/or assembly of data; C - data analysis and interpretation; \\ $D$ - writing the article; $E$ - critical revision of the article; $F$ - final approval of the article
}

Address for correspondence

Agnieszka Szymczyk

E-mail:agnieszka.szymczyk.med@wp.pl

\section{Funding sources}

None declared

\section{Conflict of interest}

None declared

Received on October 29, 2016

Reviewed on January 28, 2017

Accepted on July 14, 2017

DOI

10.17219/acem/75903

Copyright

Copyright by Author(s)

This is an article distributed under the terms of the

Creative Commons Attribution Non-Commercial License

(http://creativecommons.org/licenses/by-nc-nd/4.0/)

\begin{abstract}
Background. Richter's syndrome (RS) is a rare complication with an unfavorable prognosis, in which chronic lymphocytic leukemia (CLL) or small lymphocytic lymphoma (SLL) transform into a more aggressive type of lymphoma, most commonly into diffuse large B cell lymphoma (DLBCL) or less often into Hodgkin's lymphoma (HL).
\end{abstract}

Objectives. The objective of this research paper was to present a retrospective analysis of patients with CLL/SLL whose disease transformed into RS.

Material and methods. The study included 217 patients (100 women and 107 men) with CLL/SLL diagnosed in the years 2006-2015 at the Department of Hematooncology and Bone Marrow Transplantation of the Medical University of Lublin, which transformed into RS. We analyzed clinical, laboratory, immunophenotypic (ZAP-70 and CD38 expression), histopathological, and genetic data (del(17p), del(11q)), which was collected at the time of CLL/SLL diagnosis, and some which was collected at the time of transformation.

Results. Richter's syndrome was diagnosed in $4.6 \%$ of all CLL and SLL patients. The group of patients with RS consisted of 9 patients with primary CLL and 1 patient with a diagnosis of SLL (8 patients with transformation into DLBCL and 2 patients with transformation into $\mathrm{HL}$ ). Leukemic lymphocytes showed evidence of peripheral blood lymphocyte membrane expression of $Z \mathrm{AP} \mathrm{O}^{+} / \mathrm{CD} 38^{+}$(1 patient), of ZAP- $70^{+} / C D 38^{-}$( 3 patients), ofZAP-70-/CD38- (1 patient), and of ZAP- $70^{-} / C D 38^{+}$(5 patients). The deletion of $11 \mathrm{q}(\mathrm{del}(11 \mathrm{q})$ ) was documented in 2 patients. In 4 cases, the location of RS was extremely rare (the thyroid gland, liver, skin, bladder, and central nervous system).

Conclusions. Richter's syndrome is a rare, but probable complication of CLL/SLL with an unfavorable prognosis, and it should be taken into account at every stage of the disease, particularly when the course of the disease is aggressive.

Key words: chronic lymphocytic leukemia, Richter's syndrome, small lymphocytic lymphoma 


\section{Introduction}

Chronic lymphocytic leukemia (CLL) is the most common type of leukemia in adults in the Western Hemisphere. The clinical course is heterogenic in nature. In many patients, the disease follows an indolent course and it does not require cytostatic treatment. ${ }^{1}$

Richter's syndrome (RS) has been defined as a separate clinical condition, which may occur following the transformation from chronic lymphocytic leukemia/small lymphocytic lymphoma (CLL/SLL) into an aggressive form of non-Hodgkin lymphoma (NHL), most commonly into diffuse large B cell lymphoma (DLBCL), particularly into the $A B C$ subtype (DLBCL-RS) or less commonly into Hodgkin's lymphoma (HL) - a Hodgkin variant of RS, HvRS. $^{2}$ Research carried out over the last few years has shown that in the majority of cases (80\%), a more aggressive subtype of DLBCL is clonally related to DLBCL. In the remaining group of patients, it is clonally independent of the DLBCL clone. ${ }^{3}$ At the same time, patients with CLL and SLL are at a higher risk of developing secondary malignancies, arising outside of the hematopoietic system. ${ }^{4}$

The term RS also refers to the transformation of indolent NHL outside of CLL/SLL; hence, it has been observed in $11-30 \%$ of patients with follicular lymphoma (FL), in $13 \%$ of patients with lymphoplasmacytic lymphoma (LPL) and in $11 \%$ of patients with marginal zone lymphoma (MZL). ${ }^{5-7}$

\section{Objectives}

The objective of this research paper was to present a retrospective analysis of patients with CLL/SLL whose disease underwent RS and who were treated at the Department of Hematooncology and Bone Marrow Transplantation of the Medical University of Lublin (Poland) between 2006 and 2015.

\section{Material and methods}

The analysis included patients with CLL/SLL diagnosed in the years 2006-2015, which transformed into RS.

In this timeframe, 217 CLL/SLL patients were hospitalized at the Department of Hematooncology and Bone Marrow Transplantation of the Medical University of Lublin (Poland). Apart from the patients with RS, 100 women and 107 men at a median age of 64.2 years (34-86 years), Rai stage 0-4 and Ann Arbor clinical stage II-IV were observed or treated.

Clinical, laboratory, immunophenotypic (ZAP-70 and CD38 expression), histopathological, and genetic data (deletion of $17 p-\operatorname{del}(17 p)$ and deletion of $11 q-\operatorname{del}(11 q))$ was collected at the time of CLL/SLL diagnosis, and some was collected at the time of transformation (genetic testing was repeated in 8 patients). Due to logistical reasons, the IgVH mutational status was not assessed.
The expression of ZAP-70 and CD38 was considered positive if it was present in more than $20 \%$ of leukemic cells. The diagnosis of RS was confirmed in every patient on the basis of a lymph node biopsy, bone marrow trephine or histopathology assessment of the extralymphatic system organs. Survival time was defined as the time from RS diagnosis until death or until the last follow-up of the patient. Tables 1 and 2 present the clinical characteristics, and the immunological and genetic parameters of all patients with CLL/SLL and patients with RS at the time of CLL/SLL diagnosis.

The current study was approved by the Ethics Committee of the Medical University of Lublin (Poland).

\section{Results}

The study group included 9 patients with primary CLL and 1 patient with a diagnosis of SLL. The patients' cohort included 6 women and 4 men with a median age of 65.4 years (54-81 years), Rai stage 0-4 and Ann Arbor stage II. Leukemic lymphocytes showed evidence of peripheral blood lymphocyte membrane expression of $\mathrm{ZAP} 70^{+} / \mathrm{CD}^{2} 8^{+}(1 \mathrm{pa}-$

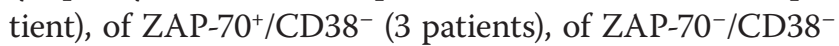
(1 patient), and of ZAP-70-/CD38+ (5 patients). The del(11q) was documented in 2 patients. Richter's syndrome was diagnosed in all patients on the basis of the lymph node biopsy of and/or a histologically proven biopsy of infiltrated tissue (8 patients with DLBCL and 2 patients with HL) involved in the pathology. The analyzed group represented $4.6 \%$ of all CLL and SLL patients treated at the Department of Hematooncology and Bone Marrow Transplantation of the Medical University of Lublin (Poland) in the years 2006-2015.

In most cases (9 patients), RS occurred during progression in the CLL/SLL phase, while in 1 patient, the disease developed at the moment of leukemia diagnosis. Systemic symptoms and increased activity of lactate dehydrogenase (LDH) were found in 9 patients.

The time from the diagnosis of CLL/SLL to the transformation ranged from 0 to 111 months (median: 42 months). Usually, 1-5 cycles of chemotherapy were administered before Richter's transformation occurred. The drugs used in chemoimmunotherapy consisted of purine analogs, alkylating agents, rituximab, ibrutinib, and idelalisib.

Five patients died during the study. Three of them did not receive cytostatic treatment due to their very poor clinical state. They survived from 2 weeks to 2 months.

The following 2 patients did not respond to chemoimmunotherapy (the disease remained active and the survival time was 1-2 months). The survival time of the remaining patients who were observed until the end of the study was 5-18 months (median: 13 months).

The treatment resulted in complete remission (CR) in 1 patient, partial remission (PR) in 2 patients and stable disease (SD) in 2 patients. The clinical characteristics of patients at the time of RS diagnosis and during transformation is presented in Tables 3 and 4. 
Table 1. Clinical characteristics, and immunological and genetic parameters of patients with CLL/SLL and RS transformation at the time of CLL/SLL diagnosis

\begin{tabular}{|c|c|c|c|c|c|c|c|}
\hline Patients & F/M ratio & $\begin{array}{l}\text { Median age } \\
\text { [years] }\end{array}$ & $\begin{array}{l}\text { Rai clinical } \\
\text { stage }\end{array}$ & $\begin{array}{l}\text { Ann Arbor } \\
\text { stage }\end{array}$ & $\begin{array}{l}\text { Immunophenotyping of leukemic } \\
\text { Iymphocyte (ZAP70/CD38) [\%] }\end{array}$ & $\begin{array}{l}\operatorname{del}(11 q) \\
{[\%]}\end{array}$ & $\begin{array}{l}\text { del TP53 } \\
{[\%]}\end{array}$ \\
\hline CLL/SLL (207) & 0.93 & 64.2 & $0-4$ & II-IV & 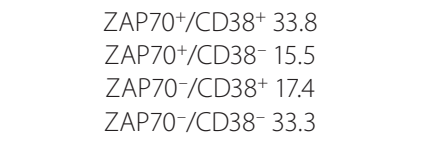 & 3.4 & 7.2 \\
\hline RS (10) & 1.5 & 65.4 & $0-4$ & $\|$ & 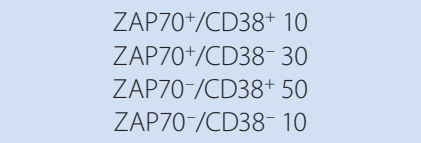 & 2 & 0 \\
\hline
\end{tabular}

CLL - chronic lymphocytic leukemia; SLL - small lymphocytic lymphoma; RS - Richter's syndrome; del - deletion; F - female; M - male.

Table 2. Clinical characteristics and immunological and genetic parameters of patients with RS at the time of CLL/SLL diagnosis

\begin{tabular}{|c|c|c|c|c|c|c|}
\hline Patient & Sex & Age [years] & $\begin{array}{l}\text { Rai clinical } \\
\text { stage }\end{array}$ & $\begin{array}{l}\text { Immunophenotyping of leukemic } \\
\text { Iymphocyte (ZAP70/CD38) }\end{array}$ & $\begin{array}{c}\text { Genetic } \\
\text { abnormalities }\end{array}$ & $\begin{array}{l}\text { Lymph nodes } \\
\qquad 3 \mathrm{~cm}\end{array}$ \\
\hline No. 1 & $\mathrm{~F}$ & 70 & 0 & ZAP70-/CD38- & del(11q) & no \\
\hline No. 2 & F & 67 & 2 & $\mathrm{ZAP}^{+} 0^{+} / \mathrm{CD} 38^{-}$ & no & yes \\
\hline No. 3 & $\mathrm{~F}$ & 58 & $\|^{*}$ & $\mathrm{ZAP} 70^{+} / \mathrm{CD} 8^{-}$ & no & yes \\
\hline No. 4 & M & 71 & 3 & ZAP70-/CD38 ${ }^{+}$ & no & yes \\
\hline No. 5 & M & 70 & 2 & ZAP70-/CD38 ${ }^{+}$ & no & yes \\
\hline No. 6 & $\mathrm{~F}$ & 60 & 1 & $\mathrm{ZAP} 70^{+} / \mathrm{CD} 38^{+}$ & no & yes \\
\hline No. 7 & M & 63 & 2 & ZAP70-/CD38+ & del(11q) & yes \\
\hline No. 8 & M & 54 & 2 & ZAP70-/CD38 ${ }^{+}$ & no & yes \\
\hline No. 9 & $\mathrm{~F}$ & 60 & 4 & ZAP70-/CD38 ${ }^{+}$ & no & yes \\
\hline No. 10 & $\mathrm{~F}$ & 81 & 3 & ZAP70-/CD38- & no & yes \\
\hline
\end{tabular}

RS - Richter's syndrome; CLL - chronic lymphocytic leukemia; SLL - small lymphocytic lymphoma; F - female; M - male; del - deletion; ${ }^{*}$ Ann Arbor staging.

Table 3. Clinical characteristics of patients at the time of RS diagnosis

\begin{tabular}{|c|c|c|c|c|c|c|c|}
\hline Patient & $\begin{array}{l}\text { Rai clinical } \\
\text { stage }\end{array}$ & B-symptoms & $\begin{array}{l}\mathrm{LDH} \\
{[\mathrm{U} / \mathrm{L}]}\end{array}$ & Phase of CLL & $\begin{array}{c}\text { CLL duration } \\
\text { [months] }\end{array}$ & Treatment of CLL & $\begin{array}{c}\text { Genetic } \\
\text { abnormalities }\end{array}$ \\
\hline No. 1 & 2 & yes & $\uparrow$ & progression & 26 & $B, B R$ & $\operatorname{del}(11 q)$ \\
\hline No. 2 & 2 & no & $\uparrow$ & progression & 12 & without treatment & no \\
\hline No. 3 & $\mathrm{IV}^{*}$ & yes & $\uparrow$ & progression & 88 & FC, CHOP, BR, ibrutynib & no \\
\hline No. 4 & 3 & yes & $\uparrow$ & progression & 48 & FC & no \\
\hline No. 5 & 4 & yes & $\uparrow$ & progression & 36 & $\mathrm{R}-\mathrm{CHOP}$ & no \\
\hline No. 6 & 2 & yes & $\uparrow$ & progression & 111 & $\mathrm{FC}, \mathrm{B}, \mathrm{CHOP}$, ibrutynib & no \\
\hline No. 7 & 4 & yes & $\uparrow$ & progression & 22 & $\mathrm{R}-\mathrm{CHOP}, \mathrm{F}, \mathrm{FC}, \mathrm{BR}$ & ND \\
\hline No. 8 & 2 & yes & N & progression & 71 & COP, CHOP, FC, F, ofatumumab + idelalisib & ND \\
\hline No. 9 & 2 & yes & $\uparrow$ & progression & 92 & ChIP & no \\
\hline No. 10 & 3 & yes & $\uparrow$ & at the time of diagnosis & 0 & without treatment & no \\
\hline
\end{tabular}

RS - Richter's syndrome; LDH - lactate dehydrogenase; CLL - chronic lymphocytic leukemia; $\uparrow$ - increases; $N$ - normal; B - bendamustine; $\mathrm{R}$ - rituximab; $\mathrm{F}$ - fludarabine; $\mathrm{C}$ - cyclophosphamide; $\mathrm{H}$ - doxorubicin; $\mathrm{O}$ - vincristine; $\mathrm{P}$ - prednisone; $\mathrm{Chl}$ - chlorambucil; del - deletion; ND - not done; ${ }^{*}$ Ann Arbor staging.

In 6 patients, the disease involved extranodal sites (the bone marrow, skin, pleura, urinary bladder, thyroid gland, liver, and central nervous system). In patient No. 9, abdominal computed tomography $(\mathrm{CT})$ revealed a considerably enlarged liver with irregular borders. The liver parenchyma, with a density of $40 \mathrm{HU}$, was almost completely infiltrated with numerous round areas of normal density and up to $70 \mathrm{~mm}$ in size, which showed smaller contrast enhancement (Fig. 1). At the same time, an ultrasound scan showed a hyperechoic, solid tumor of the left lobe and isthmus of the thyroid gland. Assessment of the bioptic material obtained from the liver and thyroid gland confirmed histologically proven DLBCL.

In patient No. 7, CT revealed an infiltrative lesion of the urinary bladder. Specimens were obtained from the trigone and neck of the bladder during cystoscopy. 
Table 4. Clinical characteristics of patients with RS diagnosis

\begin{tabular}{|c|c|c|c|c|c|c|c|}
\hline Patient & $\begin{array}{l}\text { Histological } \\
\text { type }\end{array}$ & Location & Symptoms/tests suggesting RS & $\begin{array}{l}\text { Treatment } \\
\text { of RS }\end{array}$ & $\begin{array}{l}\text { Response } \\
\text { to treatment }\end{array}$ & $\begin{array}{c}\text { RS } \\
\text { duration } \\
\text { [months] }\end{array}$ & $\begin{array}{l}\text { Status during } \\
\text { last observation } \\
\text { (alive: yes/no) }\end{array}$ \\
\hline No. 1 & DLBCL & skin & lumpy lesions on the skin, fever & $\mathrm{BR}$ & progression & 2 & no \\
\hline No. 2 & DLBCL & lymph nodes & progressive lymphadenopathy, fever & $\mathrm{R}-\mathrm{CHOP}$ & $P R$ & 13 & yes \\
\hline No. 3 & $\mathrm{HL}$ & $\begin{array}{l}\text { lymph nodes, bone } \\
\text { marrow }\end{array}$ & progressive lymphadenopathy, fever & $\begin{array}{l}\text { without } \\
\text { treatment }\end{array}$ & NA & 2 & no \\
\hline No. 4 & $\mathrm{HL}$ & lymph nodes & $\begin{array}{l}\text { progressive lymphadenopathy, fever, } \\
\text { night sweats }\end{array}$ & $A B V D$ & progression & 1 & no \\
\hline No. 5 & $D L B C L$ & lymph nodes, pleura & $\begin{array}{l}\text { progressive lymphadenopathy, } \\
\text { dyspnoea, cough/chest CT scan }\end{array}$ & $\begin{array}{c}\text { B + Bleo } \\
\text { intrapleural }\end{array}$ & PR & 18 & yes \\
\hline No. 6 & $B L B C L$ & lymph nodes & $\begin{array}{l}\text { progressive lymphadenopathy, night } \\
\text { sweats }\end{array}$ & $\mathrm{R}-\mathrm{CHOP}$ & SD & 5 & yes \\
\hline No. 7 & DLBCL & urinary bladder & $\begin{array}{c}\text { fever, abdominal pain/abdominal } \\
\text { CT scan }\end{array}$ & $\begin{array}{l}\text { without } \\
\text { treatment }\end{array}$ & NA & 1 & no \\
\hline No. 8 & DLBCL & central nervous system & $\begin{array}{c}\text { disturbances of consciousness/ } \\
\text { cranial CT scans }\end{array}$ & $\begin{array}{l}\text { without } \\
\text { treatment }\end{array}$ & NA & 0.5 & no \\
\hline No. 9 & DLBCL & $\begin{array}{l}\text { lymph nodes, thyroid } \\
\text { gland, liver }\end{array}$ & $\begin{array}{l}\text { weight loss, abdominal pain/chest } \\
\text { and abdominal CT scan }\end{array}$ & $\mathrm{R}-\mathrm{CHOP}$ & $C R$ & 13 & yes \\
\hline No. 10 & DLBCL & lymph nodes & $\begin{array}{l}\text { progressive lymphadenopathy, night } \\
\text { sweats }\end{array}$ & $\mathrm{COP}$ & SD & 5 & yes \\
\hline
\end{tabular}

RS - Richter's syndrome; DLBCL - diffuse large B cell lymphoma; HL - Hodgkin's lymphoma; CT - computed tomography; B - bendamustine; R - rituximab; $\mathrm{C}$ - cyclophosphamide; $\mathrm{H}$ - doxorubicin; $\mathrm{O}$ - vincristine; $\mathrm{P}$ - prednisone; A - adriamycin; $\mathrm{V}$ - vinblastine; D - dacarbazine; Bleo - bleomycin; CR - complete remission; PR - partial remission; SD - stable disease; NA - not applicable.

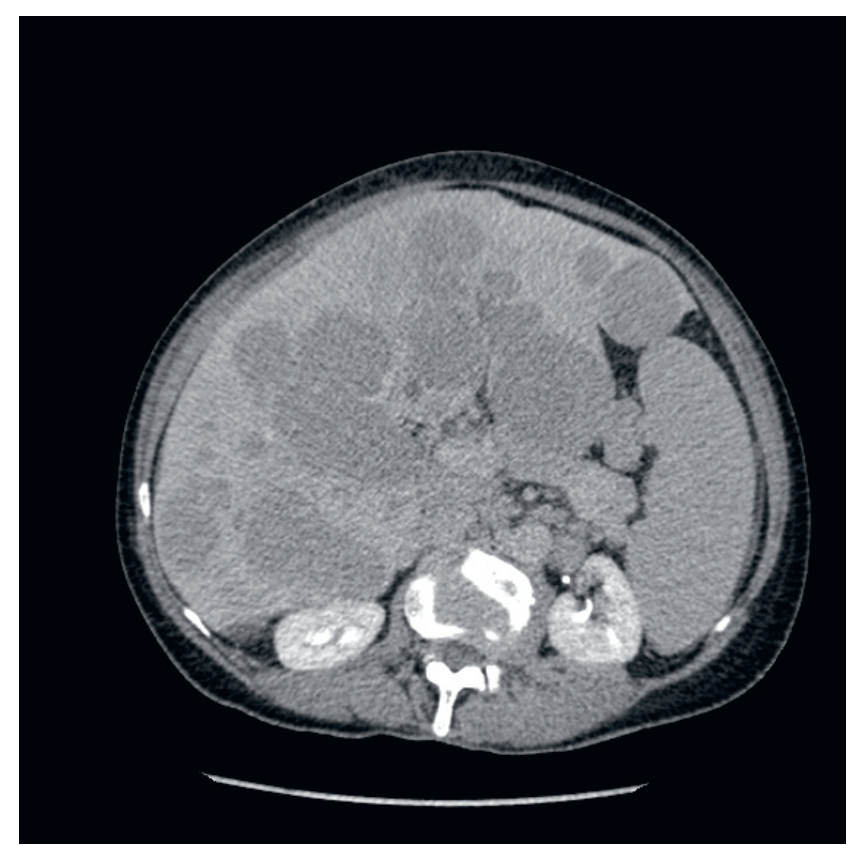

Fig. 1. Computed tomography (CT) scan of the liver of patient No. 9

Histopathological assessment of the obtained material confirmed the diagnosis of DLBCL. Patient No. 8 presented with a neurological deficit, so a head and skull CT scan was performed. The scan revealed an $18 \times 16 \mathrm{~mm}$ lesion with evidence of contrast enhancement in the right cavernous sinus. The diagnosis of DLBCL was made on autopsy. In patient No. 1, physical examination revealed red, lumpy lesions on the skin of the eyelids (Fig. 2), forearms and abdomen (Fig. 3). Histology skin specimens were obtained, following assessment by a dermatology consultant. A histopathological examination of the biopsy specimen results showed RS disease transformation.

\section{Discussion}

Richter's syndrome is a rare complication which was first described by Maurice Richter in $1928 .^{8}$ The incidence of RS in patients with CLL has been estimated to be between $2 \%$ and $10 \% .^{9}$ In our study, the incidence of the disease was $4.6 \%$. This remarkable discrepancy of the data may be due to patient selection of different referral centers and to the high heterogeneity of the patient groups, which probably included both patients with histopathologically confirmed disease and patients with clinically suspected RS. ${ }^{10}$

Clinical studies, the source of information about RS, do not always deliver reliable data on the incidence of the disease, as they usually describe only selected patient groups (of a certain age, clinical status or history of chemotherapy). They usually include patients with progressive forms of the disease who require intensive treatment. ${ }^{11-14}$

Contrary to the opinion that RS usually starts after a few years of CLL, Parikh et al. showed in their study that the median time to transformation was only 1.8 years. The authors of the publication suggest that the predisposition to RS may be congenital. ${ }^{15}$

The TP53 and CDKN2A mutations were found in about $50 \%$ of patients with RS, while the trisomy 12 and NOTCH1 mutations were identified in $30 \%$ of patients. ${ }^{16}$ The genetic 
instability and loss of cell cycle control, related to c-MYC abnormalities, may explain the mechanisms of transformation. Infection with the Epstein-Barr virus is indicated as the factor dysregulating the immune system in patients with HvRS. ${ }^{17}$

There are numerous controversies over the impact of previous therapies on the clonal selection process. Some cytostatic agents may be considered triggers in the development of RS. Patients with CLL/SLL are usually administered many different types of chemotherapy, which means that it is difficult to identify which drug is of particular significance for the RS disease transformation. Treatment with a combination of purine analogues and alkylating agents has been reported to have an adverse effect on the development of the disease, whereas the risk of RS did not appear to be increased in patients exposed to only 1 of these drug classes. ${ }^{15}$ On the other hand, Catovsky et al. and Solh et al. did not observe this effect in their studies. ${ }^{11,14}$

Little is known about the role of the small molecules, such as ibrutinib, idelalisib, BCL-2, and GDC-199 antagonists. In the study by Woyach et al., who investigated ibrutinib used in monotherapy and in combination with ofatumumab, RS developed in $6 \%$ of patients (in $2 / 3$ of them, RS occurred within the $1^{\text {st }}$ year of the treatment). ${ }^{18}$

In our study group, RS was found in 2 patients receiving ibrutinib and developed after 4-5 months of the therapy. It appears that it is not possible at the moment to suggest the impact of the drug on the development of RS. The mechanism of clonal evolution should also be taken into account. In cases where the duration of treatment was short, it is also possible that transformation started before the therapy was initiated. An increased risk of RS is associated with adverse prognostic factors, which include genetic aberrations such as $\operatorname{del}(11 q), \operatorname{del}(17 p)$, unmutated immunoglobulin heavy chain variable region genes (IGHV), and a high expression of ZAP-70, CD38 and CD49d at the moment of CLL diagnosis. ${ }^{15,19,20}$ Recent studies have also suggested the significance of the NOTCH1 mutation, which considerably increases the risk of transformation (20-30\% in patients with the mutation vs $5 \%$ in patients without the mutation). It has also been proven that it concerns only the cases of clonally related RS. ${ }^{21,22}$

In our study, del(11q) was found in 2 patients, whereas leukemic B-cells showed expression of ZAP-70 and CD38 in 9 patients. It appears that not all adverse prognostic factors correlate with the development of RS. Rossi et al. proved that biological and molecular pathways leading to RS transformation and to the aggressive course of CLL differ from one another. They showed in their study that the SF3B1 mutation, which is the latest marker of CLL progression, did not have any impact on RS transformation. ${ }^{22}$

An additional argument supporting this hypothesis is the fact that in 1 of our patients, RS developed at the moment of CLL diagnosis, when the disease was in the stable stage. The clinical course of RS is usually aggressive and

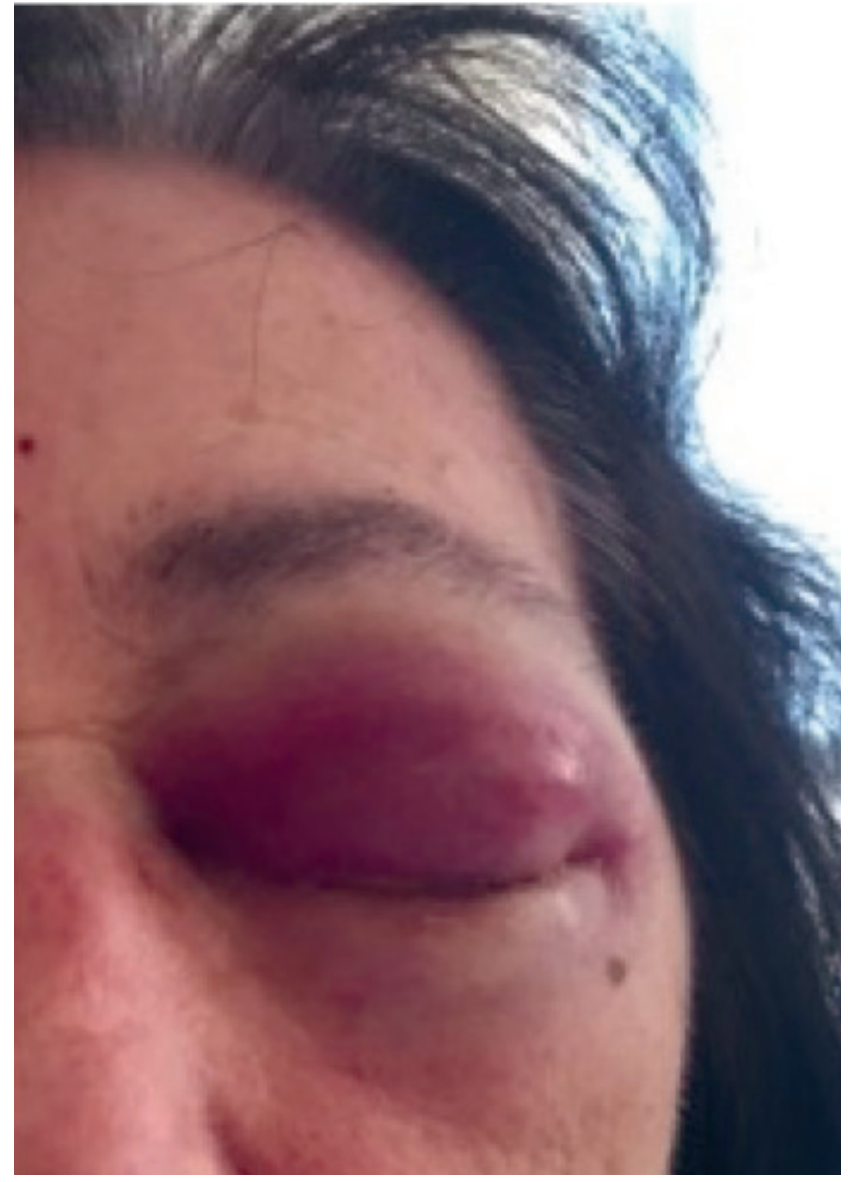

Fig. 2. Red, lumpy lesions on the skin of the eyelids of patient No. 1

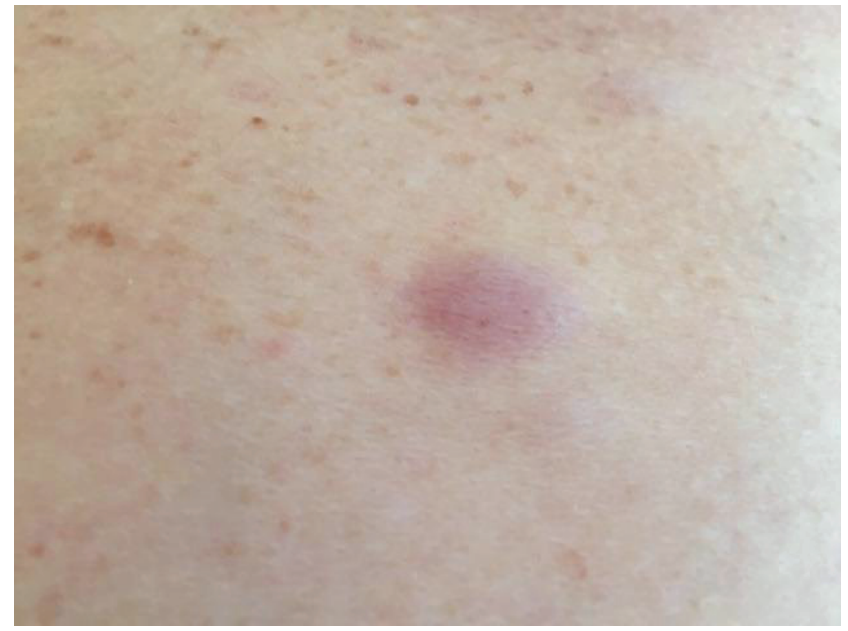

Fig. 3. Changes on the skin of the forearms and abdomen of patient No. 1

extremely rapid. The clinical picture of DLBCL-RS is similar to that of HvRS. More than half of the patients (59\%) present with fever, considerable weight loss and drenching night sweats. Progressive lymphadenopathy, usually of 1 region, is observed in $64 \%$ of patients, while elevated LDH levels and monoclonal gammopathy are observed in $82 \%$ and $44 \%$ of patients, respectively. ${ }^{23,24}$ Hypercalcemia is also sometimes observed. ${ }^{25}$ These symptoms are not specific to RS and they may be associated with CLL progression. 
One examination which helps to diagnose $\mathrm{RS}$ is positron emission tomography (PET). A maximum standard uptake value $\left(\mathrm{SUV}_{\text {max }}\right)>5$ indicates the potential location of the transformation, but it still requires confirmation by a histopathological examination, due to the need to exclude prolymphocytic leukemia, a coexisting lymphoma of different histology, the lymph node involvement by inflammation, or an unrelated malignancy. ${ }^{26,27}$

Richter's syndrome most often affects lymph nodes and bone marrow. The disease is located extranodally in $41 \%$ of patients. The prognosis for patients with CLL/SLL who were diagnosed with RS is extremely poor. It concerns typical DLBCL transformation as well as HvRS. ${ }^{24}$ At the same time, there are some differences in the clinical course of the disease depending on which risk group, defined by Tsimberidou et al., the patient belongs to. ${ }^{10}$ The "Richter score" was based on the platelet levels, LDH levels, Eastern Cooperative Oncology Group (ECOG) performance status, a tumor size $>5 \mathrm{~cm}$, and more than 1 prior cycle of chemotherapy. However, it did not take into account genetic aberrations which often occur during the course of the disease or clonality, which are probably the most important factor. The prognosis of the less common clonally unrelated RS seems to be significantly better. ${ }^{3}$ An extranodal location of the disease also appears to be an important factor in prognosis. In our study, the disease was found in the central nervous system - a particularly poor prognostic location. The evaluation of clonality requires precise testing methods. The examination of the rearranged IGVH $\mathrm{VH}-\mathrm{D}$-JH nucleotide sequence by polymerase chain reaction and sequencing is currently considered the best one. It is not possible, however, to perform these tests in every healthcare center. ${ }^{19}$

The studied group included 130 patients with CLL/SLL diagnosed within the 5-year period (2012-2016) in the Department of Hematooncology of the Oncology Center in Brzozów (Poland) and followed by one of the researchers from our team. Out of this group, 4 patients with CLL suffered transformation into RS.

A poor prognosis in RS mainly results from the resistance to chemotherapy, which is often caused by genetic aberrations, particularly those acquired during the course of the disease. There are no prospective studies of patients with RS and it considerably complicates the development of effective treatment regimens. The results of the molecular studies which provide an explanation of the transformation mechanisms are not sufficiently used for therapeutic purposes. The most commonly used treatment regimen for DLBCL-RS is R-CHOP (rituximab, cyclophosphamide, doxorubicin, vincristine, prednisone), whereas for HvRS it is ABVD (adriamycin, bleomycin, vinblastine, and dacarbazine) and less frequently MOPP (mechlorethamine, oncovin, procarbazine, and prednisone). ${ }^{28,29}$

Recently, more attention has been paid to new molecules. It is especially true in regard to ibrutinib, which could be used in transplant-eligible patients with RS who showed resistance to previous chemoimmunotherapy. ${ }^{30}$ New antibodies are also promising. One clinical study (MC1485), which evaluated the efficacy of PD-1 antibodies in resistant and recurrent forms of CLL and low-grade B-NHL, showed good response to the treatment in patients with RS. ${ }^{31}$ In patients with the location of the disease in the central nervous system or with other solitary lesions, radiotherapy should be taken into consideration. An autologous or allogeneic stem cell transplant may also be considered.

\section{Summary}

Richter's syndrome is an uncommon complication of CLL/SLL with an unfavorable prognosis. Richter's syndrome should be considered at any time of the disease presentation, even at diagnosis - particularly when the course of the disease is aggressive (severe general symptoms, massive lymphadenopathy and internal organ involvement). There is currently no clear therapeutic algorithm for the treatment of the disease. Richter's syndrome occurs most often in elderly patients suffering from comorbid conditions and it often develops after a few cycles of chemotherapy. Treatment of active and aggressive forms of the disease is particularly difficult and cumbersome. Targeted therapies, based on the knowledge of the mechanisms of transformation, seem to give hope for the future. The RS treatment process requires further intensive research.

\section{References}

1. Dighiero G, Hamblin TJ. Chronic lymphocytic leukaemia. Lancet. 2008;371(9617):1017-1029.

2. Campo E, Swerdlow SH, Harris NL, Pileri SA, Stein H, Jaffe ES. The 2008 WHO classification of lymphoid neoplasms and beyond: Evolving concepts and practical applications. Blood. 2011;117(19):5019-5032.

3. Rossi D, Spina V, Deambrogi C, et al. The genetics of Richter syndrome reveals disease heterogeneity and predicts survival after transformation. Blood. 2011;11(12):3391-3401.

4. Travis LB, Curtis RE, Hankey BF, Fraumeni JF Jr. Second cancers in patients with chronic lymphocytic leukemia. J Natl Cancer Inst. 1992;84(18):1422-1427.

5. Link BK, Maurer MJ, Nowakowski GS, et al. Rates and outcomes of follicular lymphoma transformation in the immunochemotherapy era: A report from the University of lowa/Mayo Clinic specialized program of research excellence molecular epidemiology resource. $J$ Clin Oncol. 2013;31(26):3272-3278.

6. Lin P, Mansoor A, Bueso-Ramos C, Hao S, Lai R, Medeiros LJ. Diffuse large B-cell lymphoma occurring in patients with lymphoplasmacytic lymphoma/Waldenström macroglobulinemia. Clinicopathologic features of 12 cases. Am J Clin Pathol. 2003;120(2):246-253.

7. Camacho Fl, Mollejo M, Mateo MS, et al. Progression to large B-cell lymphoma in splenic marginal zone lymphoma: A description of a series of 12 cases. Am J Surg Pathol. 2001;25(10):1268-1276.

8. Richter MN. Generalized reticular cell sarcoma of lymph nodes associated with lymphatic leukemia. Am J Pathol. 1928;4(4):285-292.

9. Parikh SA, Kay NE, Shanafelt TD. How we treat Richter syndrome. Blood. 2014;123:1647-1657.

10. Tsimberidou AM, O'Brien S, Khouri I, et al. Clinical outcomes and prognostic factors in patients with Richter's syndrome treated with chemotherapy or chemoimmunotherapy with or without stem-cell transplantation. J Clin Oncol. 2006;24(15):2343-2351. 
11. Catovsky D, Richards S, Matutes E, et al. Assessment of fludarabine plus cyclophosphamide for patients with chronic lymphocytic leukaemia (the LRF CLL4 Trial): A randomised controlled trial. Lancet. 2007;370(9583):230-239.

12. Flinn IW, Neuberg DS, Grever MR, et al. Phase III trial of fludarabine plus cyclophosphamide compared with fludarabine for patients with previously untreated chronic lymphocytic leukemia: US Intergroup Trial E2997. J Clin Oncol. 2007;25(7):793-798.

13. Keating MJ, O'Brien S, Lerner S, et al. Long-term follow-up of patients with chronic lymphocytic leukemia (CLL) receiving fludarabine regimens as initial therapy. Blood. 1998;92(4):1165-1171.

14. Solh M, Rai KR, Peterson BL, et al. The impact of initial fludarabine therapy on transformation to Richter syndrome or prolymphocytic leukemia in patients with chronic lymphocytic leukemia: Analysis of an intergroup trial (CALGB 9011). Leuk Lymphoma. 2013;54(2):252-254.

15. Parikh SA, Rabe KG, Call TG, et al. Diffuse large B-cell lymphoma (Richter syndrome) in patients with chronic lymphocytic leukaemia (CLL): A cohort study of newly diagnosed patients. Br J Haematol. 2013;162(6):774-782.

16. Chigrinova E, Rinaldi A, Kwee I, et al. Two main genetic pathways lead to the transformation of chronic lymphocytic leukemia to Richter syndrome. Blood. 2013;122(15):2673-2682.

17. Dolcetti R, Carbone A. Epstein-Barr virus infection and chronic lymphocytic leukemia: A possible progression factor? Infect Agent Cancer. 2010;5:22. doi: 10.1186/1750-9378-5-22

18. Woyach JA, Ruppert AS, Lozanski G, et al. Association of disease progression on ibrutinib therapy with the acquisition of resistance mutations: A single-center experience of 267 patients. J Clin Oncol. 2014;32:5s (suppl; abstract 7010).

19. Rossi D, Cerri M, Capello D, et al. Biological and clinical risk factors of chronic lymphocytic leukaemia transformation to Richter syndrome. Br J Haematol. 2008;142(2):202-215.

20. Jain N. New developments in Richter syndrome. Clin Adv Hematol Oncol. 2015;13(4):220-222.
21. Rossi D, Bruscaggin A, Spina V, et al. Mutations of the SF3B1 splicing factor in chronic lymphocytic leukemia: Association with progression and fludarabine-refractoriness. Blood. 2011;118(26):6904-6908.

22. Rossi D, Rasi S, Spina V, et al. Different impact of NOTCH1 and SF3B1 mutations on the risk of chronic lymphocytic leukemia transformation to Richter syndrome. Br J Haematol. 2012;158(3):426-429.

23. Swords R, Bruzzi J, Giles F. Recent advances in the diagnosis and therapy of Richter's syndrome. Med Oncol. 2007;24(1):17-32.

24. Tsimberidou AM, Keating MJ. Richter syndrome: Biology, incidence, and therapeutic strategies. Cancer. 2005;103(2):216-228.

25. Robertson LE, Pugh W, O'Brien S, et al. Richter's syndrome: A report on 39 patients. J Oncol. 1993;11(10):1985-1989.

26. Hallek M, Cheson BD, Catovsky D, et al. Guidelines for the diagnosis and treatment of chronic lymphocytic leukemia: A report from the International Workshop on Chronic Lymphocytic Leukemia updating the National Cancer Institute-Working Group 1996 guidelines. Blood. 2008;111(22):5446-5456.

27. Kuppers R, Duhrsen U, Hansmann ML. Pathogenesis, diagnosis, and treatment of composite lymphomas. Lancet Oncol. 2014;15(10):435-446.

28. Jenke P, Eichhorst B, Busch R, et al. Cyclophosphamide, adriamycin, vincristine and prednisone plus rituximab (CHOP-R) in fludarabine $(F)$ refractory chronic lymphocytic leukemia (CLL) or CLL with autoimmune cytopenia (AIC) or Richter's transformation (RT): Final analysis of a phase II study of the German CLL Study Group. Blood. 2011;118:abstract 2860.

29. Bockorny B, Codreanu I, Dasanu CA. Hodgkin lymphoma as Richter transformation in chronic lymphocytic leukaemia: $A$ retrospective analysis of world literature. Br J Haematol. 2012;156(1):50-66.

30. Rossi D. Richter's syndrome: Novel and promising therapeutic alternatives. Best Pract Res Clin Haematol. 2016;29(1):30-39.

31. Ding W, Dong H, Call TG, et al. PD-1 blockade with pembrolizumab (MK-3475) in relapsed/refractory CLL including Richter transformation: An early efficacy report from a phase 2 trial (MC1485). Blood. 2015;126:843. 